\title{
ESR studies of nitrogen atoms stabilized in aggregates of krypton-nitrogen nanoclusters immersed in superfluid helium
}

\author{
S. Mao ${ }^{1}$, R.E. Boltnev ${ }^{2}$, V.V. Khmelenko ${ }^{1}$, and D.M. Lee ${ }^{1}$ \\ ${ }^{1}$ Department of Physics and Astronomy, Texas A\&M University, College Station TX 77843, USA \\ E-mail:khmel@physics.tamu.edu \\ ${ }^{2}$ Branch of Institute of Energy Problems of Chemical Physics, Chernogolovka, Moscow Region 142432, Russia
}

Received June 12, 2012

\begin{abstract}
Impurity-helium condensates (IHCs) containing nitrogen and krypton atoms immersed in superfluid ${ }^{4} \mathrm{He}$ have been studied via a CW electron spin resonance (ESR) technique. The IHCs are gel-like aggregates of nanoclusters composed of impurity species. It was found that the addition of krypton atoms to the nitrogen-helium gas mixture used for preparation of IHCs increases efficiency of stabilization of nitrogen atoms. We have achieved high average $\left(5 \cdot 10^{19} \mathrm{~cm}^{-3}\right)$ and local $\left(2 \cdot 10^{21} \mathrm{~cm}^{-3}\right)$ concentrations of nitrogen atoms in kryptonnitrogen-helium condensates. The analysis of ESR lines shows that three different sites exist for stabilization of nitrogen atoms in krypton-nitrogen nanoclusters. Nitrogen atoms are stabilized in the krypton core of nanoclusters, in the nitrogen molecular layer which covers the $\mathrm{Kr}$ core and on the surface of the nanoclusters. High concentrations of nitrogen atoms achieved in IHCs provide an important step in the search for magnetic ordering effects at low temperatures.
\end{abstract}

PACS: 67.80.--s Quantum solids;

61.46-w Structure of nanoscale materials;

76.30.Rn Free radicals;

76.30.--v Electron paramagnetic resonance and relaxation.

Keywords: impurity-helium condensates, electron spin resonance technique, nanoclusters.

\section{Introduction}

Early studies of matrix isolation of atomic free radicals at cryogenic temperatures were performed in a program initiated at the U.S. National Bureau standards in the 1950's. The goal of this work was to develop highly energetic materials for potential use as rocket fuels. Various techniques were developed to study samples formed in this research including optical spectroscopy, electron spin resonance (ESR), and x-ray diffraction. A comprehensive summary of the early work performed in this field has been provided in the book edited by Bass and Broida [1]. Although considerable new physics was uncovered, the goal of obtaining high enough concentrations for any conceivable applications was elusive. In the studies described, the concentrations above $1 \%$ of atomic nitrogen embedded in molecular nitrogen matrices were never obtained.

A new era in achieving high concentrations of free radicals in cryogenic matrix isolation research was ushered in the experiment of E.B. Gordon, L.P. Mezhov-Deglin and O.F. Pugachev, the results of which were published in 1974 [2]. The experiment was conducted in Chernogolovka, Russia (then the Soviet Union). The group developed a method which allowed them to achieve record concentrations of matrix isolated free radicals. The method involved introducing a gas mixture at room temperature into a quartz tube extending down into a region cooled to superfluid helium temperatures. Electrodes were placed around the tube near its lower end for the purpose of dissociating gas molecules via a radiofrequency discharge into their atomic free radical constituents. The gas emerged into the main liquid helium region where it condensed into a sample beaker whose superfluid helium level was maintained by a fountain pump connecting to the main helium bath. The method is favorable for the creation of very high concentrations of stabilized atoms because of the efficient cooling of the atoms by cold helium vapor, the rapid heat transfer by superfluid helium from the region of the sample formation and the high specific heat of liquid helium, which minimizes temperature increases from events involving the recombination of free atoms. This method not only allowed exceptionally high concentrations of stabilized atoms (up 
to $10 \%$ atomic nitrogen in $\mathrm{N}-\mathrm{N}_{2}$ samples) [3] but also provided for a variety of significant experiments. Optical spectroscopy [4-9], ESR [10-18], x-ray diffraction [19-23] and ultrasound techniques [24-27] were used to characterize these samples and to determine why free radical stabilization was so effective. It was found that the samples of impurity helium condensates formed inside superfluid helium have a porous structure composed of nanoclusters of impurity species with characteristic size of order $5 \mathrm{~nm}$ [19]. The impurity clusters are surrounded by layers of solid helium and the porous structure is filled with superfluid helium. Recent studies of deuterium-helium [28] and hydrogen-krypton-helium [29] condensates revealed that majority of stabilized atoms reside on the surfaces of nanoclusters of impurities. Also, it was found that the addition of $\mathrm{Kr}$ atoms in condensed gas mixture substantially increased the concentration of stabilized hydrogen and deuterium atoms [29-31].

In this work we studied the effect of adding $\mathrm{Kr}$ atoms to nitrogen-helium gas mixtures with the goal of achieving the highest possible concentration of stabilized nitrogen atoms.

\section{Experimental setup}

The experimental setup for investigating stabilized atoms in IHCs at low temperatures based on the technique discussed above was described in more detail elsewhere [16]. The experiments were performed in a specially designed Janis cryostat with a variable temperature insert (VTI), which is a separate chamber, thermally insulated from the main $4 \mathrm{~K}$ helium bath. A needle valve connects the main helium bath of the cryostat to the VTI. Pumping on the VTI, while supplying liquid helium from the main bath, permits long-term investigations of impurity-helium condensates at temperatures above $1.2 \mathrm{~K}$. The lower part of the cryostat was placed between the pole pieces of a homogeneous Varian electromagnet for CW ESR investigations. Impurity-helium condensates with stabilized atoms for ESR investigations were prepared in situ in the Janis cryostat. The homemade insert [16] for formation and investigation of atoms contained in IHCs was used in this work. For sample preparation, a gas mixture of $\mathrm{N}_{2}, \mathrm{Kr}$ and $\mathrm{He}$ was transported from a room temperature gas handling system to the cryogenic region. To provide the $\mathrm{N}$ atoms via dissociation of the gas molecules, a high power radiofrequency $(f \sim 50 \mathrm{MHz}, P \sim 70 \mathrm{~W})$ was applied to electrodes around the quartz capillary carrying the mixed gases. The resulting jet of helium gas with a small fraction $(0.5 \%)$ of impurity atoms and molecules emerging from the quartz capillary was directed onto the surface of superfluid ${ }^{4} \mathrm{He}$ contained in a small beaker suspended above the VTI helium bath. The addition of helium gas increased the efficiency of dissociation of impurity molecules in the discharge due to interaction between the impurity and metastable $\mathrm{He}$ atoms, and also retarded agglomeration of impurity atoms and molecules in the gas jet. The jet penetrated the surface of the liquid helium and a macroscopic snow-like translucent material was created. This material fell down through the liquid ${ }^{4} \mathrm{He}$ to form a porous solid at the bottom of the beaker. A fountain pump connected to the bottom of the helium bath in the VTI maintained a constant liquid helium level in the beaker. The temperature during sample preparation was $1.5 \mathrm{~K}$. At the top of the beaker was a funnel that caught the sample as it condensed below the helium surface, which was $2 \mathrm{~cm}$ below the end of the quartz capillary. A set of Teflon blades [13] scraped the sample from the funnel while the beaker was rotated so that the sample could fall to the bottom of the narrow cylindrical part of the beaker. A jet with a flux of $\sim 5 \cdot 10^{19}$ atoms and molecules per second yielded $\sim 0.3-0.4 \mathrm{~cm}^{3}$ of sample in $10 \mathrm{~min}$.

In independent $x$-ray scattering studies of the $\mathrm{N}_{2}-\mathrm{He}$ samples, it was shown that these samples consisted of nanoclusters of $\mathrm{N}_{2}$ molecules, each surrounded by thin layers of solid helium $[19,20]$. The typical nitrogen cluster size is estimated to be $\sim 5 \mathrm{~nm}$. These nanoclusters assemble into a porous gel-like structure. From the comparison of the intensity of the $\mathrm{N}_{2}$ cluster peak with the intensity of the scattering from liquid helium, the molecular nitrogen densities in these samples was found to be of order $10^{20} \mathrm{~cm}^{-3}$.

After sample preparation, the beaker containing the sample was lowered into the ESR cavity through a hole in the cavity specially designed to fit the lower, cylindrical part of the sample beaker. The homemade cylindrical cavity was operated in the $\mathrm{TE}_{011}$ mode and was situated at the bottom of the cryostat in the homogeneous field region of the Varian 7800 electromagnet. The quality factor of the cavity was equal to 3000 . The volume occupied by the sample inside the cavity was $0.35 \mathrm{~cm}^{3}$. CW ESR signals were obtained for samples immersed in liquid helium at temperatures $\sim 1.35 \mathrm{~K}$, and they were recorded by a continuous wave reflection homodyne spectrometer (Bruker 300) operating near $8.92 \mathrm{GHz}$. Derivatives of the ESR absorption lines were detected at $\sim 0.32 \mathrm{~T}$ by lock-in amplification using an additional small amplitude modulation field oscillating at $100 \mathrm{kHz}$. Atomic concentrations were measured by comparing the intensity of the atomic signals with the intensity of a signal from a small ruby crystal that was used as a secondary standard. The ruby crystal was attached permanently to the bottom of the microwave cavity. The calibration of the absolute value of the number of spins in the ruby crystal was made by using a standard organic diphenyl-picrylhydrazil (DPPH) sample with a known number $\left(\sim 2.4 \cdot 10^{17}\right)$ of spins. The measurements were carried out at $T=1.35 \mathrm{~K}$. A nuclear magnetic resonance (NMR) magnetometer was used for precise measurements of the applied magnetic field. The microwave carrier frequency was precisely measured by using a frequency counter «EIP 545» while the field was swept through the resonance. 


\section{Results}

We studied the effect of the addition of $\mathrm{Kr}$ atoms in the nitrogen-helium gas mixture on the efficiency of stabilization of $\mathrm{N}$ atoms in IHCs. In Fig. 1 we display ESR spectra of $\mathrm{N}$ atoms contained in different IHCs samples at $1.35 \mathrm{~K}$. Curve 1 corresponds to the sample prepared from gas mixture $\left[\mathrm{N}_{2}\right] /[\mathrm{Kr}] /[\mathrm{He}]=1 / 5 / 1200$. Curve 2 corresponds to the sample prepared from gas mixture $\left[\mathrm{N}_{2}\right] /[\mathrm{He}]=1 / 1200$. In these gas mixtures the ratio between the nitrogen molecules and helium was kept equal to 1/1200. In the experimental runs a series of ESR spectra of $\mathrm{N}$ atoms were recorded at $T=1.35 \mathrm{~K}$ for each sample. From this figure the effect of increasing the efficiency of stabilization of $\mathrm{N}$ atoms by adding $\mathrm{Kr}$ atoms to the condensed nitrogen-helium gas mixture is clearly seen. Firstly, the intensity of the ESR signal from $\mathrm{N}$ atoms is $\sim 6$ times larger for the sample formed with addition of $\mathrm{Kr}$ atoms indicating a substantial increase in the average concentration of $\mathrm{N}$ atoms in the sample. Secondly, unusually broad wings are seen in this signal, showing significant increase of the local concentration of stabilized $\mathrm{N}$ atoms.

With the goal of achieving maximum possible concentrations of stabilized $\mathrm{N}$ atoms in nitrogen-krypton-helium condensates, we studied the effect of adding different quantities of $\mathrm{Kr}$ gas to the condensed nitrogen-helium gas mixtures. The ratio between impurity species $\left(\left[\mathrm{N}_{2}\right]+[\mathrm{Kr}]\right)$ and $\mathrm{He}$ in the gas mixture was kept constant and equal to $1 / 200$. However, the ratio of nitrogen molecules to krypton atoms, $\left[\mathrm{N}_{2}\right] /[\mathrm{Kr}]$, in the mixture was changed from $1 / 50$ to 4/1. In Fig. 2 the ESR spectra of $\mathrm{N}$ atoms in nitrogenkrypton-helium samples prepared with different $\left[\mathrm{N}_{2}\right] /[\mathrm{Kr}]$ ratios are shown. We obtained well resolved ESR spectra of $\mathrm{N}$ atoms stabilized in the IHCs sample prepared from the gas mixture $\left[\mathrm{N}_{2}\right] /[\mathrm{Kr}] /[\mathrm{He}]=1 / 50 / 10000$ (Fig. 2(a)).

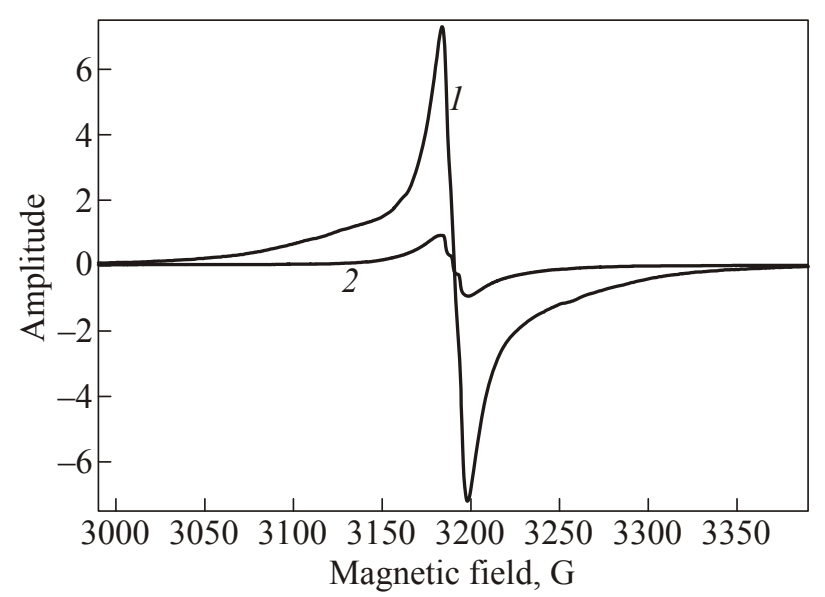

Fig. 1. ESR spectra of $\mathrm{N}$ atoms in an as-prepared $\mathrm{N}-\mathrm{N}_{2}-\mathrm{Kr}-\mathrm{He}$ sample at $1.35 \mathrm{~K}(1)$. The sample was prepared from a gas mixture with ratio $\left[\mathrm{N}_{2}\right] /[\mathrm{Kr}] /[\mathrm{He}]=1 / 5 / 1200$. ESR spectra of $\mathrm{N}$ atoms in as-prepared $\mathrm{N}-\mathrm{N}_{2}-\mathrm{He}$ sample at $1.35 \mathrm{~K}$ (2). The sample was prepared from a gas mixture with ratio $\left[\mathrm{N}_{2}\right] /[\mathrm{He}]=1 / 1200$.

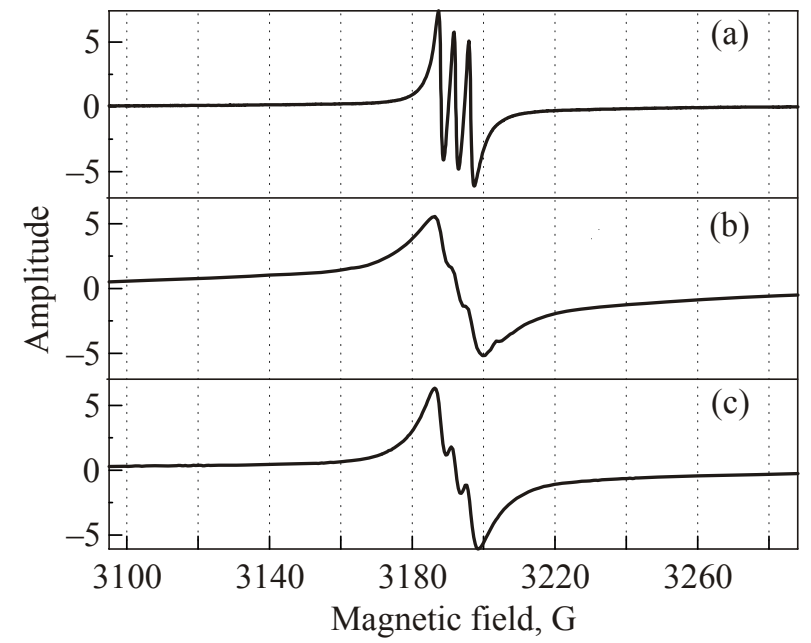

Fig. 2. ESR spectra of $\mathrm{N}$ atoms in as-prepared $\mathrm{N}-\mathrm{N}_{2}-\mathrm{Kr}-\mathrm{He}$ samples prepared from different gas mixtures: from gas mixture $\left[\mathrm{N}_{2}\right] /[\mathrm{Kr}] /[\mathrm{He}]=1 / 50 / 10000$ (a); from gas mixture $\left[\mathrm{N}_{2}\right] /[\mathrm{Kr}] /[\mathrm{He}]=$ $=1 / 5 / 1200(\mathrm{~b})$; from gas mixture $\left[\mathrm{N}_{2}\right] /[\mathrm{Kr}] /[\mathrm{He}]=1 / 1 / 400$ (c). All spectra were obtained at $T=1.35 \mathrm{~K}$.

Less resolved, broad ESR spectra of $\mathrm{N}$ atoms were detected for the sample prepared from the gas mixture $\left[\mathrm{N}_{2}\right] /[\mathrm{Kr}] /[\mathrm{He}]=1 / 5 / 1200$. Further increase of the $\left[\mathrm{N}_{2}\right] /[\mathrm{Kr}]$ ratio in the condensed gas mixture led to a decrease of the intensity and less broadening of the $\mathrm{N}$ atom signal.

The results of the measurements of the average concentrations of $\mathrm{N}$ atoms in nitrogen-krypton-helium condensates prepared by using different $\left[\mathrm{N}_{2}\right] /[\mathrm{Kr}]$ ratios are shown in Fig. 3. For some gas mixtures, experiments were performed by using different values of the flux, ranging from $4.6 \cdot 10^{19}$ to $5.4 \cdot 10^{19} \mathrm{~s}^{-1}$. Only the highest measured concentrations for each of the mixtures employed are presented in Fig. 3. It has been found that the best results for stabilization of $\mathrm{N}$ atoms were obtained for the highest flux

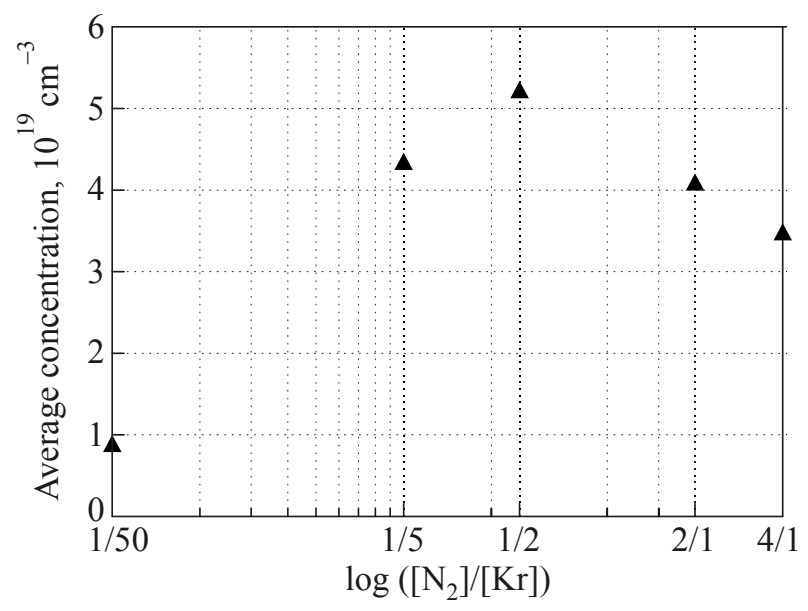

Fig. 3. Dependence of average concentration of $\mathrm{N}$ atoms stabilized in nitrogen-krypton-helium samples on the ratio of $\mathrm{N}_{2} / \mathrm{Kr}$ in various gas mixtures. The ratio between the impurity species $\left(\left[\mathrm{N}_{2}\right]+[\mathrm{Kr}]\right)$ and $\mathrm{He}$ in the gas mixture was kept equal to $1 / 200$ for all gas mixtures used for preparation IHCs samples. 
used, $5.4 \cdot 10^{19} \mathrm{~s}^{-1}$. The largest average concentrations, of order $5.3 \cdot 10^{19} \mathrm{~cm}^{-3}$, were achieved for the gas mixture $\left[\mathrm{N}_{2}\right] /[\mathrm{Kr}] /[\mathrm{He}]=1 / 2 / 600$. This value is more than double the highest value achieved in IHCs prepared from nitrogenhelium gas mixtures [32] without the addition of $\mathrm{Kr}$ atoms.

As a result of the high concentration of $\mathrm{N}$ atoms achieved in $\mathrm{N}-\mathrm{Kr}-\mathrm{He}$ condensates, the atomic separation is short enough for the formation of nitrogen spin pair radicals. The strong dipole forces associated with unpaired spins make it favorable for two spins separated by distances less than $1 \mathrm{~nm}$ to flip simultaneously. This corresponds to the $\Delta M=2$ transition of spin pair radicals, for which two spins in the pair simultaneously change their orientation in the magnetic field due to absorption of one microwave photon. In our experiment, we observed ESR signals for $\mathrm{N} \cdots \mathrm{N}$ spin pair radicals in $\mathrm{N}-\mathrm{Kr}-\mathrm{He}$ condensates. The ESR spectra of the $\mathrm{N}$ atoms and $\mathrm{N} \cdots \mathrm{N}$ spin pair radicals are shown in Fig. 4. Spectra of $\mathrm{N}^{\cdots} \mathrm{N}$ spin pair radicals were observed at half the field compared to the main $\mathrm{N}$ atom transition. The ratio between the intensities of the main atomic line and the line of spin pair radicals was found to be 1875 in the experiment. The first observation of $\mathrm{N}^{\cdots} \mathrm{N}$ spin pair radicals in a neon matrix at $T=4.2 \mathrm{~K}$ was made by Knight et al. [33] and later our group observed the signal of $\mathrm{N} \cdots \mathrm{N}$ spin pair radicals in nitrogen-helium condensates at $T=$ $=1.35 \mathrm{~K}[34]$.

We studied the behavior of $\mathrm{N}$ atoms in nitrogenkrypton-helium samples during the annealing process. After observation of "as-prepared" samples were made at $T=$ $=1.35 \mathrm{~K}$, the samples were gradually heated to $20 \mathrm{~K}$. As the first step, we removed liquid helium from the sample cell at $T=2.8 \mathrm{~K}$ and performed measurements of $\mathrm{N}$ atoms in these "dry" IHCs. Usually all of the $\mathrm{N}$ atoms survived during the drying process at $T=2.8 \mathrm{~K}$, and sometimes we observed an increase in the intensity of the $\mathrm{N}$ atom signals due to collapsing of the pores in the sample which led to an increase in the sample density and allowed an additional amount of sample to enter the sensitive zone of the ESR cavity. Upon further increase in temperature of the samples, the broad feature of the signal disappeared and only a small signal remained, which corresponded to the atoms

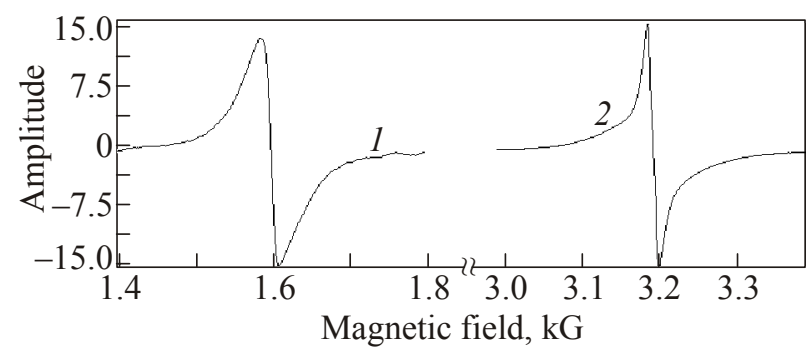

Fig. 4. ESR spectra of spin pair radicals (1) and individual nitrogen atoms (2) in $\mathrm{N}-\mathrm{Kr}-\mathrm{He}$ condensate at $T=1.35 \mathrm{~K}$. Intensity of spin pair radicals line was multiplied by a factor of 1875 . The spectra are obtained in the sample prepared with the gas mixture $\mathrm{N}_{2} / \mathrm{Kr} / \mathrm{He}=4 / 1 / 1000$.

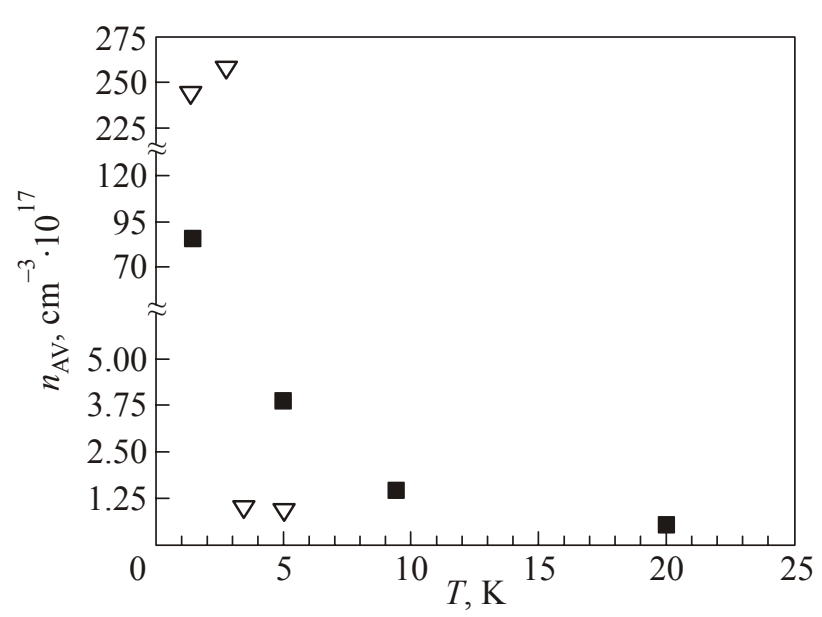

Fig. 5. Dependence of average concentration of $\mathrm{N}$ atoms on the temperature for samples prepared from gas mixtures $\left[\mathrm{N}_{2}\right] /[\mathrm{Kr}] /[\mathrm{He}]=1 / 50 / 10000(\mathbf{m})$ and $\left[\mathrm{N}_{2}\right] /[\mathrm{Kr}] /[\mathrm{He}]=1 / 2 / 600(\nabla)$.

stabilized in the $\mathrm{Kr}$ matrix. During sample annealing, rapid diffusion occurred for the $\mathrm{N}$ atoms residing on the surface of the nanoclusters, initiating an explosive recombination of the $\mathrm{N}$ atoms. This led to sublimation of a substantial part of the sample, which was accompanied by bright light flashes $[9,35]$. Only a small fraction of the initial clusters agglomerated into larger crystallites, preserving a small population of $\mathrm{N}$ atoms trapped in the $\mathrm{Kr}$ matrices. The explosive destruction of the $\mathrm{N}-\mathrm{Kr}-\mathrm{He}$ samples with high concentrations of $\mathrm{N}$ atoms occurred at temperatures in the range 3.5-5 K. Dependence of the average concentration on temperature during annealing of nitrogen-kryptonhelium samples prepared from gas mixtures with ratios $\left[\mathrm{N}_{2}\right] /[\mathrm{Kr}] /[\mathrm{He}]=1 / 50 / 10000$ and $1 / 2 / 600$ is shown in Fig. 5. In the sample prepared with the former mixture, $\mathrm{N}$ atoms were observed even at $T \sim 20 \mathrm{~K}$, while for the latter mixture, a signal was observed only up to $T \sim 5 \mathrm{~K}$. Figure 6

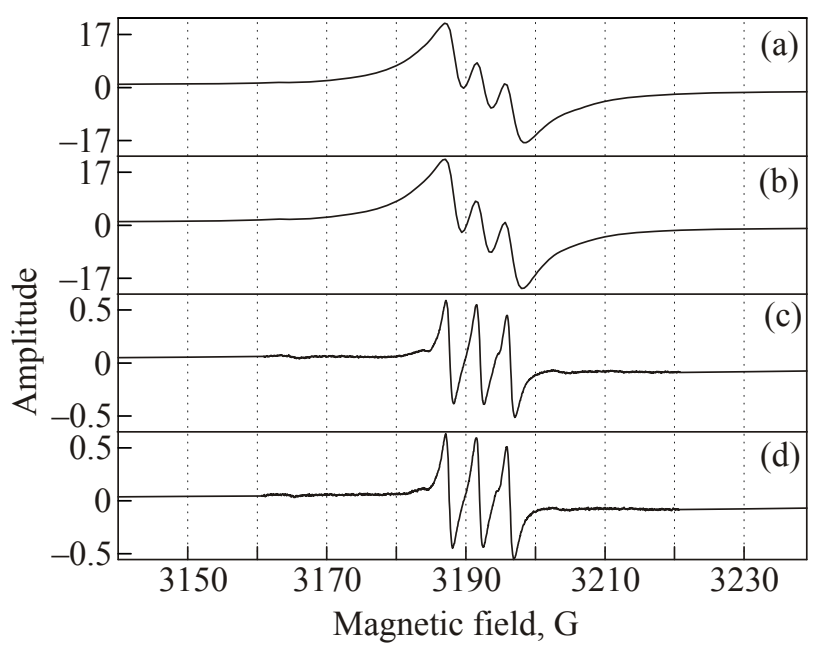

Fig. 6. Transformation of ESR spectra of nitrogen atoms stabilized in samples prepared with gas mixture $\left[\mathrm{N}_{2}\right] /[\mathrm{Kr}] /[\mathrm{He}]=$ $=1 / 2 / 600$. Spectra were obtained at different temperatures $T, \mathrm{~K}$ : $1.401(\mathrm{a}), 2.8$ (b), 3.5 (c) and $5.02(\mathrm{~d})$. 


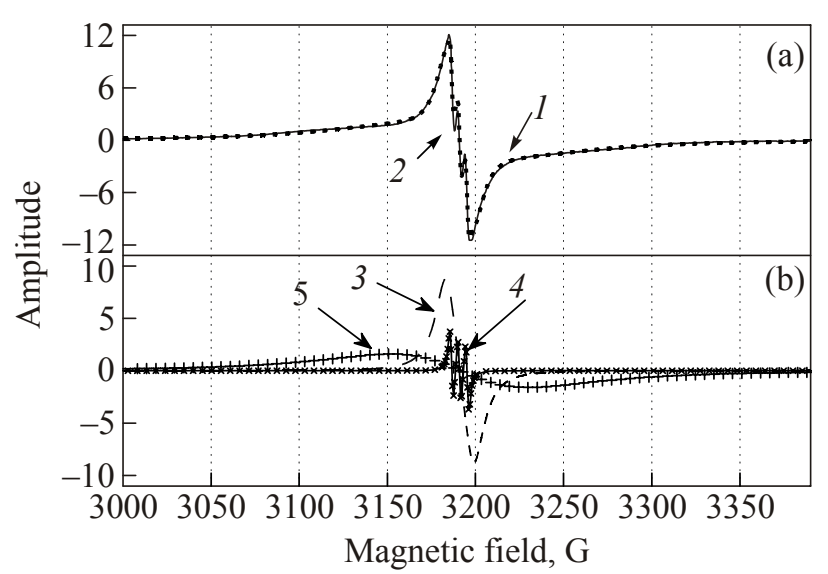

Fig. 7. Experimental ESR spectrum of $\mathrm{N}$ atoms for as-prepared nitrogen-krypton-helium sample formed by gas mixture $\left[\mathrm{N}_{2}\right] /[\mathrm{Kr}] /[\mathrm{He}]=1 / 2 / 600$ is shown as a solid line (1). The sum of the fitting lines is shown as a dotted line (2) (a). Three triplets of fitting lines used for decomposition of the experimental ESR spectrum: 3-triplet of Lorentzian lines with line width $9.47 \mathrm{G}$ and hyperfine splitting, $A=4.97 \mathrm{G}$, 4-triplet of Lorentzian lines with line width $1.99 \mathrm{G}$ and $A=4.39 \mathrm{G}, 5$-triplet of Lorentzian lines with line width $76.97 \mathrm{G}$ and $A=4.12 \mathrm{G}$. The weights of each triplet in the spectra were found to be $13.5,0.6$ and $84.4 \%$, respectively (b).

shows the transformations of the $\mathrm{N}$ atom ESR spectra during annealing of the samples prepared with gas mixture $\left[\mathrm{N}_{2}\right] /[\mathrm{Kr}] /[\mathrm{He}]=1 / 2 / 600$. The spectra became more and more resolved with increasing temperature due to a reduction in the concentrations of stabilized $\mathrm{N}$ atoms in the samples, leading to a reduced dipole-dipole interaction of the atoms.

The characteristic features of the spectra of $\mathrm{N}$ atoms in as-prepared samples of $\mathrm{N}-\mathrm{Kr}-\mathrm{He}$ condensates are the broad wings and weak triplet at the central part (see curve 1 in Fig. 1). All these features of spectra obtained for as-prepared samples were fitted with a sum of three triplets of Lorentzian lines as shown in Fig. 7. The fitting process was performed by a Graphic User Interface (GUI) program written in Matlab. This GUI program can simulate the experimental signal using up to eight Lorentzian/Gaussian function components. It automatically searches the best hyperfine splitting constant and linewidth for each component. When difference between the simulated curves and the experimental curve becomes minimal, it stops searching and give the corresponding parameters. Figure 7(a) shows an experimental ESR spectrum for $\mathrm{N}$ atoms in an IHCs prepared from a gas mixture $\left[\mathrm{N}_{2}\right] /[\mathrm{Kr}] /[\mathrm{He}]=$ $=1 / 2 / 600$, and the sum of fitting lines which provide a rather good fit to the experiment. Figure 7(b) shows three fitting lines composed from the triplets with different hyperfine splittings and line widths. Each of the triplets is assigned to the atoms in specific environment. A similar analysis was performed for all spectra obtained for different nitrogen-krypton-helium condensates. The results of this analysis are presented in Table 1.

In Table 2 the spectroscopic characteristics of $\mathrm{N}$ atoms in different matrices are shown. These results were obtained from earlier studies [36-43]. The spectroscopic characteristics for $\mathrm{N}$ atoms as obtained from the fitting procedure were compared with the characteristics for $\mathrm{N}$ atoms in different matrices shown in Table 2. From these comparisons we found that there are three separate groups of $\mathrm{N}$ atoms in a given sample each stabilized in a different environment. We identify triplet 3 in Fig. 7(b) with $\mathrm{N}$ atoms trapped in the $\mathrm{Kr}$ matrix $(g=2.0021, A=4.39 \mathrm{G})$; the narrow triplet 4 in Fig. 7(b) is assigned to the $\mathrm{N}$ atoms inside the $\mathrm{N}_{2}$ layer $(g=2.0019, A=4.97 \mathrm{G})$ and the broad trip-

Table 1. Hyperfine structure constants, $A, g$ factors, peak to peak widths, $\Delta H_{p p}$, and local concentrations for $\mathrm{N}$ atoms in $\mathrm{N}-\mathrm{Kr}-\mathrm{He}$ condensates obtained from ESR lines fittings

\begin{tabular}{c|c|c|c|c|c|c}
\hline \hline Sample & Curve type & $A, \mathrm{G}$ & $\Delta H_{p p}, \mathrm{G}$ & Local concentration, $\mathrm{cm}^{-3}$ & Weight, \% & $g$ factor \\
\hline \hline$[\mathrm{N} 2]:[\mathrm{Kr}]:[\mathrm{He}]=$ & Lorentzian & 4.12 & 23.25 & $6.28 \cdot 10^{20}$ & 74.9 & 2.0011 \\
$=1: 50: 10000$ & Lorentzian & 4.39 & 2.185 & $5.90 \cdot 10^{19}$ & 25 & 2.0011 \\
& Lorentzian & 4.2 & 0.4544 & $1.23 \cdot 10^{19}$ & 0.1 & 2.0011 \\
\hline$[\mathrm{N} 2]:[\mathrm{Kr}]:[\mathrm{He}]=$ & Lorentzian & 4.12 & 67.44 & $1.82 \cdot 10^{21}$ & 86 & 2.0022 \\
$=1: 5: 1000$ & Lorentzian & 4.39 & 3.375 & $9.11 \cdot 10^{19}$ & 0.8 & 2.0022 \\
& Lorentzian & 4.97 & 11.85 & $3.20 \cdot 10^{20}$ & 13.5 & 2.0017 \\
\hline$[\mathrm{N} 2]:[\mathrm{Kr}]:[\mathrm{He}]=$ & Lorentzian & 4.12 & 76.97 & $2.08 \cdot 10^{21}$ & 84.4 & 2.0019 \\
$=1: 2: 600$ & Lorentzian & 4.39 & 1.995 & $5.39 \cdot 10^{19}$ & 0.6 & 2.0021 \\
& Lorentzian & 4.97 & 9.471 & $2.56 \cdot 10^{20}$ & 15 & 2.0019 \\
\hline$[\mathrm{N} 2]:[\mathrm{Kr}]:[\mathrm{He}]=$ & Lorentzian & 4.12 & 74.95 & $2.02 \cdot 10^{21}$ & 83.5 & 2.0020 \\
$=2: 1: 600$ & Lorentzian & 4.39 & 9.603 & $2.59 \cdot 10^{20}$ & 16.4 & 2.0020 \\
& Gaussian & 4.2 & 1.829 & $4.94 \cdot 10^{19}$ & 0.1 & 2.0020 \\
\hline$[\mathrm{N} 2]:[\mathrm{Kr}]:[\mathrm{He}]=$ & Lorentzian & 4.12 & 62.74 & $1.69 \cdot 10^{21}$ & 85.6 & 2.0019 \\
$=4: 1: 1000$ & Lorentzian & 4.39 & 10.99 & $2.97 \cdot 10^{20}$ & 14.3 & 2.0019 \\
& Gaussian & 4.2 & 2.093 & $5.65 \cdot 10^{19}$ & & 0.1 \\
\hline \hline
\end{tabular}


Table 2. Hyperfine structure constants, A, and $g$ factors for $\mathrm{N}$ atoms in $\mathrm{N}_{2}$ and $\mathrm{Kr}$ matrices

\begin{tabular}{c|c|c|c}
\hline \hline Matrix & $\mathrm{A}, \mathrm{G}$ & $\left(\mathrm{A}_{\text {free }}-\mathrm{A}\right) / \mathrm{A}_{\text {free }}(\%)$ & $g$ factor \\
\hline \hline Free [36] & 3.73 & 0 & $2.00215(3)$ \\
$\mathrm{N}_{2}$ (subst.) [37] & 4.31 & 15.6 & $2.00200(6)$ \\
$\mathrm{N}_{2}$ (subst.) [38] & 4.22 & 13.6 & $2.002155(5)$ \\
$\mathrm{N}_{2}$ (subst.) [39] & 4.21 & 13.4 & $2.00201(12)$ \\
$\mathrm{N}_{2}$ (subst.) [40] & 4.25 & 14.0 & $2.00200(6)$ \\
$\mathrm{N}_{2}$ (interst.) [40] & 4.85 & 30.1 & $2.00100(6)$ \\
$\mathrm{N}_{2}$ (interst.) [40] & 4.5 & 20.67 & $2.00000(6)$ \\
$\mathrm{Kr}$ (subst.) [41] & 4.47 & 19.8 & 2.0012 \\
$\mathrm{Kr}$ (subst.) [42] & 4.4 & 17.9 & 2.0019 \\
$\mathrm{Kr}$ (subst.) [43] & 4.39 & 17.7 & $2.0021(6)$ \\
\hline \hline
\end{tabular}

let 5 in Fig 7(b) corresponds to $\mathrm{N}$ atoms on the surface of the $\mathrm{N}_{2}$ layer $(g=2.0019, A=4.12 \mathrm{G})$. We assigned latter triplet to $\mathrm{N}$ atoms on the surface of $\mathrm{N}_{2}$ layer because the $A$ value for these atoms is equal to $4.12 \mathrm{G}$, which is between the value for $\mathrm{N}$ in $\mathrm{N}_{2}(4.2 \mathrm{G})$ and that for the free $\mathrm{N}$ atoms $(A=3.73 \mathrm{G})$. We assigned the $\mathrm{N}$ atoms with $A$ values equal to $4.2 \mathrm{G}$ to substitutional sites in $\mathrm{N}_{2}$ matrix and the $\mathrm{N}$ atoms with $A=4.97 \mathrm{G}$ to interstitial sites in $\mathrm{N}_{2}$ matrix.

This is the first time during investigations of matrix isolated atoms that such broad ESR signals were observed. The line width of the signal assigned to the $\mathrm{N}$ atoms on the surfaces of the nanoclusters was found to be in the range 60-78 G for different samples. Dipolar magnetic interaction of electron spins is the dominant line broadening mechanism in this system. The local concentration of $\mathrm{N}$ atoms might be estimated from formula: $n_{l}=2.7 \cdot 10^{19} \Delta H_{p p}$, where $\Delta H_{p p}$ is the peak to peak width of the ESR lines in Gauss and $n_{l}$ is the local concentration of the atoms per $\mathrm{cm}^{3}$ [44]. Estimates of the local concentrations of $\mathrm{N}$ atoms for various samples are shown in Table 1 . The highest local concentrations of $\mathrm{N}$ atoms $\left(\sim 2 \cdot 10^{21} \mathrm{~cm}^{-3}\right)$ were achieved in the samples prepared with gas mixtures $\mathrm{N}_{2}: \mathrm{Kr}: \mathrm{He}=1: 2: 600$ and $\mathrm{N}_{2}: \mathrm{Kr}: \mathrm{He}=2: 1: 600$.

We found also that addition of $\mathrm{Kr}$ atoms to $\mathrm{N}_{2}-\mathrm{He}$ gas mixtures lead to increasing the overall efficiency of stabilization of $\mathrm{N}$ atoms produced in an RF discharge. For example, for a gas mixture $\mathrm{N}_{2}: \mathrm{Kr}: \mathrm{He}=1: 50: 10000$, the efficiency of $\mathrm{N}$ atom capture is $44 \%$, whereas for gas mixtures with the ratios $\mathrm{N}_{2}: \mathrm{Kr}: \mathrm{He}=1: 5: 1200$ and $\mathrm{N}_{2}: \mathrm{Kr}: \mathrm{He}=$ $=4: 1: 1000$, the efficiencies of $\mathrm{N}$ atom capture are 25 and $5 \%$, respectively.

\section{Discussion and conclusion}

This study demonstrates the advantages of the method of injecting atoms into superfluid helium for producing samples with high concentrations of stabilized atoms. The addition of $\mathrm{Kr}$ atoms to the condensed $\mathrm{N}_{2}-\mathrm{He}$ gas mixture leads to a record high average $\left(\sim 5 \cdot 10^{19} \mathrm{~cm}^{-3}\right)$ and local $\left(\sim 2 \cdot 10^{21} \mathrm{~cm}^{-3}\right)$ concentration of stabilized $\mathrm{N}$ atoms in
$\mathrm{N}-\mathrm{Kr}-\mathrm{He}$ condensates. Observation of three different types of the environments for $\mathrm{N}$ atoms in $\mathrm{N}-\mathrm{Kr}-\mathrm{He}$ condensates might be explained by a shell structure of the nanoclusters which formed the IHCs. Such a situation was predicted [45] and later was established for atomic hydrogen atoms in matrix isolated $\mathrm{H}-\mathrm{Kr}$ clusters [29-31]. During injection of the nitrogen-krypton-helium jet into bulk superfluid helium at the early stages of cooling in the jet, the $\mathrm{Kr}$ atoms form clusters due to strong Van der Waals interaction between the $\mathrm{Kr}$ atoms. At the next stage, the $\mathrm{N}_{2}$ molecules and $\mathrm{N}$ atoms bind to the surface of the $\mathrm{Kr}$ nanoclusters. The resulting structure of krypton-nitrogen clusters is shown in Fig. 8. From the results of an analysis of the shapes of the ESR spectra, we can conclude that part of the $\mathrm{N}$ atoms $(0.6-25 \%)$ reside inside the $\mathrm{Kr}$ clusters, another portion of the $\mathrm{N}$ atoms reside in $\mathrm{N}_{2}$ layer $(0.1-15 \%)$ covering the $\mathrm{Kr}$ core and the vast majority of the $\mathrm{N}$ atoms (75-85\%) reside on the surfaces of $\mathrm{N}_{2}$ layers. Thus the highest concentration of $\mathrm{N}$ atoms appears to be in this outer surface layer.

A great deal of progress has been made in the field of matrix isolation since the early experiments by Gordon, Mezhov-Deglin and Pugachev in 1974 [2]. In the present paper, we have described recent success in obtaining exceptionally high local and average concentrations of nitrogen atoms in impurity-helium condensates. Local concentrations of $2 \cdot 10^{21} \mathrm{~cm}^{-3}$ and average concentrations of $5 \cdot 10^{19} \mathrm{~cm}^{-3}$ were achieved. This means that a very large amount of chemical energy can be stored in these samples, with energies comparable to or exceeding those stored in the best chemical explosives. The energy released by the recombination of two nitrogen atoms into a nitrogen molecule is $9.8 \mathrm{eV}$. The $\mathrm{N}$ atoms were mainly localized on the surfaces of the nanoclusters with much smaller populations contained in the cluster interiors. The ESR line shapes for $\mathrm{N}-\mathrm{Kr}$ samples differed from those of $\mathrm{N}-\mathrm{N}_{2}$ samples, possibly indicating a different distribution of $\mathrm{N}$ atoms in the nanoclusters for the two cases.

The observed concentrations were high enough to permit observation of $\Delta M=2$ spin pair radical transitions corresponding to half the Larmor field used to observe the main ESR line. Dipolar coupling between nearby atoms is responsible for this phenomenon. The large size of the ESR signal for spin pair radicals indicates that a significant fraction of $\mathrm{N}$ atoms are participating in this process. This would suggest the possibility that magnetic phase transi-

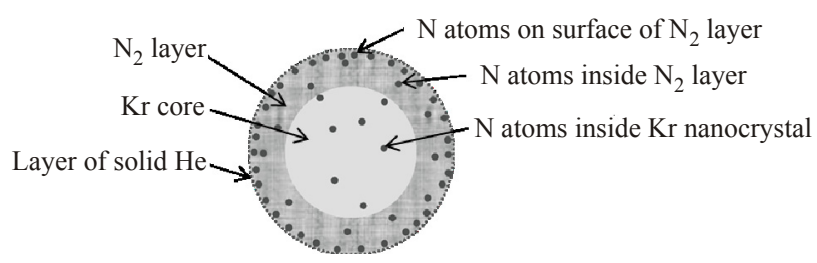

Fig. 8. Structure of nitrogen-krypton-helium nanoclusters with stabilized $N$ atoms. 
tions will occur at lower temperatures. It is also possible that if somewhat higher local concentrations can be achieved, the effect of exchange narrowing, a short range phenomenon, might be observed in this system.

We take this opportunity to thank Adil Meraki, Patrick McColgan and Trevor Dragon for assembling experimental setup and participation in the experiments.

The work was supported by grant № 010366-0137-2009 Norman Hackerman Advanced Research Program, CRDF grant RUP1-7025-CG-11, RFBR grant 11-02-92500-CRDFE_a, and federal contract 11.519.11.6021 with Russian Federation Ministry of Education and Science.

1. A.M. Bass and H.P. Broida, Formation and Trapping of Free Radicals, Academic Press, New York, London (1960).

2. E.B. Gordon, L.P. Mezhov-Deglin, and O.F. Pugachev, JETP Lett. 19, 63 (1974).

3. E.B. Gordon, V.V. Khmelenko, A.E. Popov, A.A. Pelmenev, and O.F. Pugachev, Chem. Phys. Lett. 155, 301 (1989).

4. E.B. Gordon, L.P. Mezhov-Deglin, O.F. Pugachev, and V.V. Khmelenko, Chem. Phys. Lett. 54, 282 (1978).

5. E.B. Gordon, A.A. Pelmenev, O.F. Pugachev, and V.V. Khmelenko, Chem. Phys. 61, 35 (1981).

6. E.B. Gordon, V.V. Khmelenko, A.A. Pelmenev, and O.F. Pugachev, Physica B \& C 108, 1311 (1981).

7. E.B. Gordon, M.V. Martynenko, A.A. Pelmenev, O.F. Pugachev, and V.V. Khmelenko, Khim. Fiz. 13, 15 (1994).

8. R.E. Boltnev, E.B. Gordon, V.V. Khmelenko, M.V. Martynenko, A.A. Pelmenev, E.A. Popov, and A.F. Shestakov, J. Chim. Phys. 92, 362 (1995).

9. R.E. Boltnev, I.N. Krushinskaya, A.A. Pelmenev, D.Yu. Stolyarov, and V.V. Khmelenko, Chem. Phys. Lett. 305, 217 (1999).

10. E.B. Gordon, A.A. Pelmenev, O.F. Pugachev, and V.V. Khmelenko, Fiz. Nizk. Temp. 8, 691 (1982) [Sov. J. Low Temp. Phys. 8, 299 (1982)].

11. E.B. Gordon, A.A. Pelmenev, O.F. Pugachev, and V.V. Khmelenko, JETP Lett. 37, 282 (1983).

12. E.B. Gordon, A.A. Pelmenev, O.F. Pugachev, and V.V. Khmelenko, Doklady Phys. Chem. 280, 145 (1985).

13. E.B. Gordon, A.A. Pelmenev, O.F. Pugachev, and V.V. Khmelenko, Fiz. Nizk. Temp. 11, 563 (1985) [Sov. J. Low Temp. Phys. 11, 307 (1985)].

14. S.I. Kiselev, V.V. Khmelenko, C.Y. Lee, and D.M. Lee, J. Low Temp. Phys. 128, 37 (2002).

15. S.I. Kiselev, V.V. Khmelenko, and D.M. Lee, Phys. Rev. Lett. 89, 175301 (2002).

16. S.I. Kiselev, V.V. Khmelenko, E.P. Bernard, and D.M. Lee, Fiz. Nizk. Temp. 29, 678 (2003) [Low Temp. Phys. 29, 505 (2003)].

17. S.I. Kiselev, V.V. Khmelenko, E.P. Bernard, C.Y. Lee, and D.M. Lee, Physica B 329-333, (2003).

18. E.P. Bernard, R.E. Boltnev, V.V. Khmelenko, and D.M. Lee, J. Low Temp. Phys. 138, 829 (2005).
19. V. Kiryukhin, B. Keimer, R.E. Boltnev, V.V. Khmelenko, and E.B. Gordon, Phys. Rev. Lett. 79, 1774 (1997).

20. S.I. Kiselev, V.V. Khmelenko, D.M. Lee, V. Kiryukhin, R.E. Boltnev, E.B. Gordon, and B. Keimer, Phys. Rev. B 65, 024517 (2002).

21. S.I. Kiselev, V.V. Khmelenko, D.M. Lee, V. Kiryukhin, R.E. Boltnev, E.B. Gordon, and B. Keimer, J. Low Temp. Phys. 126, 235 (2002).

22. E.P. Bernard, R.E. Boltnev, V.V. Khmelenko, V. Kiryukhin, S.I. Kiselev, and D.M. Lee, J. Low Temp. Phys. 134, 169 (2004).

23. E.P. Bernard, R.E. Boltnev, V.V. Khmelenko, V. Kiryukhin, S.I. Kiselev, and D.M. Lee, Phys. Rev. B 69, 104201 (2004).

24. S.I. Kiselev, V.V. Khmelenko, D.A. Geller, D.M. Lee, and J.R. Beamish, J. Low Temp. Phys. 119, 357 (2000).

25. S.I. Kiselev, V.V. Khmelenko, D.A. Geller, J.R. Beamish, and D. Lee, Physica B 284, 105 (2000).

26. S.I. Kiselev, V.V. Khmelenko, and D.M. Lee, Fiz. Nizk. Temp. 26, 874 (2000) [Low Temp. Phys. 26, 641 (2000)].

27. S.I. Kiselev, V.V. Khmelenko, and D.M. Lee, J. Low Temp. Phys. 121, 671 (2000).

28. E.P. Bernard, V.V. Khmelenko, and D.M. Lee, J. Low Temp. Phys. 150, 516 (2008).

29. R.E. Boltnev, E.P. Bernard, J. Jarvinen, V.V. Khmelenko, and D.M. Lee, Phys. Rev. B 79, 180506(R) (2009).

30. R.E. Boltnev, E.P. Bernard, J Jarvinen, I.N. Krushinskaya, V.V. Khmelenko, and D.M. Lee, J. Low Temp. Phys. 158, 468 (2010).

31. R.E. Boltnev, V.V. Khmelenko, and D.M. Lee, Fiz. Nizk. Temp. 36, 484 (2010) [Low Temp. Phys. 36, 382 (2010)].

32. E. P. Bernard, R.E. Boltnev, V.V. Khmelenko, and D.M. Lee, J. Low Temp. Phys. Phys. 143, 199 (2004).

33. L.B. Knight, Jr., B.A. Bell, D.P. Cobranchi, and E.R. Davidson, J. Chem. Phys. 111, 3145 (1999).

34. V.V. Khmelenko, H. Kunttu and D.M. Lee, J. Low Temp. Phys. Phys. 148, 1 (2007).

35. V.V. Khmelenko, I.N. Krushinskaya, R.E. Boltnev, I.B. Bykhalo, A.A. Pelmenev and D.M. Lee, Fiz. Nizk. Temp. 38, 871 (2012) [Low Temp. Phys. 38, 688 (2012)].

36. M.A. Heald and R. Beringer, Phys. Rev. 96, 645 (1954).

37. S.N. Foner, C.K. Jen, E.L. Cochran, and V.A. Bower, J. Chem. Phys. 28, 351 (1958).

38. Yu.A. Dmitriev and R.A. Zhitnikov, Fiz. Nizk. Temp. 24, 58 (1998) [Low Temp. Phys. 24, 44 (1998)].

39. P.H.H. Fisher, S.W. Charles, and C.A. McDowell, J. Chem. Phys. 46, 2162 (1967).

40. D.D. Delannoy, B. Tribollet, F. Valadier, and A. Erbeia, J. Chem. Phys. 68, 2252 (1978).

41. D.M. Lindsay, J. Chem. Phys. 81, 3356 (1984).

42. J. Eloranta, K. Vaskonen, H. Hakkanen, T. Kiljunen, and H. Kunttu, J. Chem. Phys. 109, 7784 (1998).

43. G.S. Jackel, W. H. Nelson, and W. Gordy, Phys. Rev. 176, 453 (1968).

44. C. Kittel and E. Abrahams, Phys. Rev. 90, 238 (1953).

45. E.B. Gordon, Fiz. Nizk. Temp. 30, 1009 (2004) [Low Temp. Phys. 30, 756 (2004)]. 